\section{REVISTA BRASILEIRA DE QUALIDADE DE VIDA}

\title{
Qualidade de Vida no Trabalho - Trabalhadores que convivem com dor crônica - o que eles esperam das empresas
}

\section{Quality of Work Life - Workers who live with chronic pain - what they expect from companies}

\author{
Aparecida Montesino Rodrigues Oliveira \\ Anhanguera Educacional - Sorocaba - Brasil \\ aparecidamontesino@ig.com.br
}

\section{Resumo}

A Responsabilidade Social das empresas na produção de um ambiente saudável, aos que convivem com a dor crônica faz parte da Qualidade de vida no trabalho (QVT). O assunto está em alta tendo em vista a preocupação com o aumento dos casos de doenças ocupacionais, a incapacidade do governo em gerir esses trabalhadores e em como as empresas devem proceder. Através do estudo de caso, o artigo divulga a pesquisa desenvolvida em uma empresa do interior de São Paulo, especificamente o programa de QVT, através da metodologia qualitativa, foram realizadas entrevistas estratificadas com trabalhadores portadores de dor crônica, consultas em prontuários médicos, laudos ergonômicos e anotações de acontecimentos no período de dois anos. O estudo comprovou que os tempos mudaram, mas a gestão de pessoas ainda está caminhando a lentos passos nessa área, isso significa que o descaso e o sofrimento dos trabalhadores fazem parte da cultura da empresa estudada e talvez de outras tantas. Ficou constatado que a empresa precisa reformular seu atual programa de QVT, que está ineficiente ao público que convive com dor crônica.

Palavras-chave: Qualidade de vida no trabalho, Saúde do trabalhador, Administração, Gestão de Pessoas.

\begin{abstract}
The Corporate Social Responsibility in the production of a healthy environment for living with chronic pain is part of the Quality of work life (QWL). The subject is high in view of concern about the increasing incidence of occupational diseases, the government's inability to manage these workers and how companies should proceed. Through the case study, the article discloses the research developed in a company of São Paulo, specifically QWL program through qualitative methodology, interviews were conducted with stratified workers with chronic pain, consultations on medical records, reports ergonomic and notes of occasions that happened within two years. The study found that times have changed, but the management of people are still walking with slow steps in this area, this means that the neglect and suffering of workers are part of the company culture studied and perhaps many others. It was found that the company needs to redesign their current program of QWL, which is inefficient to the public living with chronic pain.
\end{abstract}

Keywords: Quality of life at work, Occupational Health, Administration, Personnel Management.

\section{Introdução}


É fato que a Qualidade de Vida no Trabalho (QVT) é tema atual e de grande importância devido os altos índices de trabalhadores acometidos de doenças ocupacionais, que não são geridos pelo governo e ganharam destaque devido ao atual contexto organizacional.

Esses trabalhadores que encaminhados ao Instituto Nacional do Seguro Social (INSS), acabam retornando para a empresa em conseqüência de sua concessão de auxilio doença cancelado, com alta para o trabalho mesmo sem condições de exercê-lo com saúde e dignidade.

Trabalhadores esses que ao serem diagnosticados com Lesão por Esforço Repetitivo (LER), Distúrbios Osteo-musculares Relacionados ao Trabalho (DORT) e lombalgias segundo a própria Previdência Social ficam deprimidos, sentindo-se incapazes, limitados e inativos, com diagnóstico de uma doença sem cura e com tratamento longo e exaustivo, ocasionando longo período de afastamento do trabalho. (DATAPREV, 2003; NUNES; MENDES, 2002).

Nesse meio fica claro a falta de gestão de ambos os lados para administrar esses trabalhadores, que acabam se sentindo humilhados com toda essa situação. Para diversos autores, cabe aos profissionais envolvidos no processo de Gestão da QVT nas empresas, o estabelecimento de diretrizes e intervenções que proporcionem melhorias num enfoque biopsicossocial, visto que finalmente o trabalhador hoje é visto de forma holística. (LIMONGI-FRANÇA, 2008; VELOSO; BOSQUETI; LIMONGI-FRANÇA, 2006; VASCONCELOS, 2001).

Limongi-França (2008) relata em seus estudos que é preciso entender o bem-estar do trabalhador e como se dá o funcionamento dos programas voltados a ele, levando em consideração o sofrimento manifestado pela dor, fadiga e diminuição da capacidade de trabalho.

Dejours, Abdoucheli e Jayet (2009) reforçam o entendimento complementando que o lado profissional consome diariamente a maior parte do tempo do ser humano, que com a exigência do mercado se esforça cada vez mais para ser melhor e atingir as expectativas do mercado de trabalho.

Em uma sociedade capitalista, o indivíduo só é produtivo quando trabalha, seu trabalho é sua dignidade. Diante disso, o trabalhador sofre a pressão psicológica de saber que ele precisa vender sua força de trabalho e sua saúde, diante do atual panorama de elevados números de doenças ocupacionais e impunidade das empresas. (NUNES; MENDES, 2002).

Vários autores relatam que para garantir a saúde do trabalhador faz-se necessário a união dos conhecimentos da área da ergonomia, saúde e medicina do trabalho e, finalmente, do próprio trabalhador que sofre a ação do trabalho, para que sejam construídos projetos com novas formas de atuação. (LIMONGI-FRANÇA, 1996; LACAZ, 2000; RUMAQUELLA, 2009).

De encontro a essa realidade basta olhar para a evolução da área de gestão de pessoas, que cada vez mais valoriza o indivíduo como diferencial competitivo nas organizações, e com isso os programas de QVT, cada vez mais buscam conhecer o trabalhador em seu ser biopsicossocial, procurando entender o trabalho e as questões biológicas (saúde física) psicológicas (saúde mental), sociais (saúde social). (CHIAVENATO, 2008; LIMONGI-FRANÇA, 1996; KANIKADAN et al., 2005; VELOSO; BOSQUETI; LIMONGI-FRANÇA, 2006).

O objetivo desse estudo é responder uma questão primordial: como as empresas devem desenvolver seus Programas de Qualidade de Vida (QV) voltados ao público que convive com dor? A presente análise estuda o caso de uma empresa familiar ' $Y$ ', situada na região de Sorocaba interior de São Paulo, que atua no ramo de fornecimento de equipamentos de transmissão digital, que possui um Programa de QVT e colaboradores que convivem nessa realidade.

\section{Conceitos de Qualidade de Vida no Trabalho}

A capacidade de trabalho está diretamente vinculada às condições de saúde, sendo assim, os autores Nunes e Mendes (2002) relatam que ter saúde suficiente ou mínima para o trabalho, é uma exigência principal do mercado, este que vem mudando a passos lentos, a maneira de garantir a saúde do trabalhador, o que em época não muito distante, imperava a saúde apenas para a produtividade necessária. 
Os campos do trabalho e da saúde ganharam força com a Constituição de 1988 tratando a saúde como questão de direito, sendo a saúde percebida, não apenas como ausência de doença, mas vista como um todo na vida das pessoas:

\begin{abstract}
Resultante das condições de alimentação, educação, salário, meio ambiente, trabalho, transporte, emprego, lazer e liberdade, acesso aos serviços de saúde. A saúde adquire assim, status de direito social, e a Saúde do Trabalhador ultrapassa os limites com os quais vinha trabalhando, dentro dos conceitos de higiene e segurança do trabalho. (MENDES, 1999 apud NUNES; MENDES, 2002, p. 1).
\end{abstract}

Dentre as inúmeras definições sobre os conceitos de QVT, as que melhores descrevem a linha de pesquisa com enfoque biopsicossocial desse artigo, em particular são dos autores Dejours (2003) e Limongi-França (1996).

O conceito biopsicossocial origina-se da Medicina Psicossomática, que propõe visão integrada, holística do ser humano, em posição à abordagem cartesiana que divide o ser humano em partes: biológicas (saúde física), psicológicas (saúde mental) e sociais (saúde social). (LIMONGIFRANÇA, 1996; VELOSO; BOSQUETI; LIMONGI-FRANÇA, 2006).

Assim, QVT pode ser é definida como "[...] um conjunto de ações de uma empresa que envolve diagnóstico e implantação de melhorias e inovações gerenciais, tecnológicas e estruturais dentro e fora do ambiente de trabalho, visando propiciar condições plenas de desenvolvimento humano para e durante a realização do trabalho". (LIMONGI-FRANÇA, 1996, apud RECHZIEGEL; VANALLE; LIMONGI-FRANÇA, 2000, p. 2).

Uma empresa que não possui um programa de QVT elaborado para preservar a saúde do trabalhador, automaticamente leva-o ao sofrimento causado pelas doenças ocupacionais e historicamente o sofrimento gera a alienação para os métodos do trabalho. (DEJOURS, 2006; RUMAQUELLA, 2009).

Para Dejours (2005), o sofrimento ocasionado pelo trabalho ocasiona uma série de mecanismos de defesa, cheio de sutilidades e criatividades, arranjos e superações das dificuldades diárias, mas que se utilizado por um período de tempo longo, acaba por se tornar uma armadilha.

Tamanha importância do trabalho na vida do sujeito que o referido autor descreve o trabalho como oportunidade de relacionamento social dos indivíduos, onde as ocasiões de sofrimentos (insatisfação e ansiedade) e desafios geram a evolução das características psicológicas, mas quando esses sofrimentos criam insatisfação e desgosto, acabam por se tornar doenças somáticas.

(DEJOURS; ABDOUCHELI; JAYET, 2009).

Para descrever as causas do sofrimento humano em relação ao trabalho, e suas reações de defesas, Dejours (2006, p. 18) em seus estudos constatou que:

Há o sofrimento dos que temem não satisfazer, não estar à altura das imposições da organização do trabalho, horários, ritmos, formação, informação, aprendizagem, nível de instrução e diploma, experiência, rapidez, aquisição de conhecimentos teóricos e práticos... Então o operário tem que se defender psiquicamente porque é a única maneira para se manter 'saudável' e ativo no emprego.

Dando continuidade em seus estudos o autor descreve que a fadiga física que acomete os trabalhadores indica que não há mais possibilidade de diminuição da insatisfação, que ocasiona uma sobrecarga de energia negativa no aparelho psicológico do ser humano, que reflete em diversas patologias. (DEJOURS, 2006; JACQUES; CODO, 2002; RODRIGUES; ALVES; SILVA, 2008).

Nesse universo existe uma luta individual e coletiva contra o sofrimento, detectada por Dejours, Abdoucheli e Jayet (2009), luta essa que acaba por levar o trabalhador a uma passividade diante do condicionamento, obtida pela interiorização da dominação social de que a organização do trabalho não pretende ser reorganizada.

Nas entrelinhas dessa realidade segundo o mesmo autor existe a estratégia do silêncio, da cegueira e da surdez, regida pelo medo de tornar visíveis suas próprias dificuldades, de se mostrar incompetente, entre outros, a saber: 
Cada um deve antes de tudo se preocupar em 'resistir'. Quanto ao sofrimento alheio, não só 'não se pode fazer nada', como também sua própria percepção constitui um constrangimento ou uma dificuldade subjetiva suplementar, que prejudica os esforços de resistência. Portanto, convém fechar os olhos e os ouvidos ao sofrimento e à injustiça infligidos a outrem. Todos os trabalhadores se defendem da mesma maneira: negando o sofrimento alheio e calando o seu. (DEJOURS, 2006, p. 51).

Nesse contexto que permeia a vida dos trabalhadores e as ferramentas para melhor gerenciálos, segundo Berlanger, é preciso melhorar as condições de trabalho, de modo a proporcionar aos indivíduos melhores condições de vida e cargos mais satisfatórios para a própria pessoa, com reflexos na produtividade (BERLANGER, 1992, apud OLIVEIRA, 2008, p. 4).

Veloso, Bosqueti e Limongi-França (2006) e demais autores evidenciam que a humanização do trabalho e o investimento em QVT correspondem às ferramentas necessárias para prevenir e reduzir os elevados números que se referem a absenteísmo (ausência de trabalhadores no processo de trabalho), acidentes e doenças do trabalho, desmotivação, insatisfação, afastamentos, enfim, uma série de situações que intervêm relativamente no desempenho profissional e organizacional. (OLIVEIRA, 2008; GRAZIANO; FARAH; GRAZIANO, 2005; RODRIGUES; ALVES; SILVA, 2008).

\section{Políticas Previdenciárias vigentes}

Segundo o Dataprev (Empresa de Tecnologia e Informação da Previdência Social) o trabalhador brasileiro alcançou em 2003 junto ao governo, uma grande conquista com relação às doenças de LER e DORT. (BELEDELI, 2010).

Foi em 1993, que o INSS publicou uma revisão de duas normas sobre LER, ampliando o seu conceito e reconhecendo como sendo um estudo de causas a organização do trabalho e aspectos biomecânicos. Em 2003, esse documento foi atualizado ao publicar a Instrução Normativa INSS/DC No 98 (Documento número 98), ainda em vigor. (BRASIL, Diário Ofícial da União, 2003).

Ao estudar mais profundamente a normativa, entende-se que o perito do INSS ao analisar casos de LER/DORT, deve ser um profissional possuidor de conhecimentos profundos de biomecânica ocupacional (ciência que estuda o movimento e a biomecânica é chamada de cinesiologia, sendo o fisioterapeuta o único profissional da saúde que tem como base em seus conhecimentos esta ciência), o que ainda não foi implantado pelo INSS, ou seja, peritos de outras especialidades médicas, que não têm respaldo clínico específico, fazem a vêz do fisioterapeuta. (DATAPREV, 2003).

Para se ter uma idéia da proporção da gravidade do problema, a falta de fiscalização e da impunidade das empresas, basta analisar os dados divulgados pelo governo, onde apenas de 2007 a 2008 - último ano com dados recolhidos pelo INSS - as notificações de acidentes no desempenho das funções cresceram 13,4\%, passando de 659.523 registros para 747.663 , segundo informações do Anuário Estatístico de Acidentes do Trabalho, publicação conjunta dos ministérios da Previdência Social e do Trabalho e Emprego. (BELEDELI, 2010).

O Brasil perde, por ano, o equivalente a $4 \%$ do PIB por causa dos acidentes de trabalho. Segundo dados do Anuário Estatístico de Acidentes de Trabalho, publicado em janeiro de 2008, foram registrados em 2007, em todo o País, 503.890 acidentes de trabalho. (FUNDACENTRO, 2008).

As notificações de doenças do sistema osteomuscular, nas quais se incluem a LER, aumentaram 512\%. Estima-se que este aumento esteja relacionado com a regularização das notificações acidentárias, segundo o Fundacentro (Fundação Jorge Duprat Figueiredo de Segurança e Medicina do Trabalho - Ministério do Trabalho e Emprego, 2008).

Em 2007, foram registrados 51,372 mil casos de dorsalgias. Em 2008, esse número subiu para 55,450 mil. Em abril de 2010, entrou em vigor em todo o Brasil o Nexo Técnico 
Epidemiológico Previdenciário, mecanismo que relaciona determinada doença às atividades profissionais nas quais ocorre com maior incidência. Desde então, o registro de doenças ocupacionais cresceu, em média, 134\%, segundo dados do Ministério da Previdência. (BELEDELI, 2010).

Desde janeiro de 2010, está em vigor uma nova legislação, que colocou em vigor a aplicação do Fator Acidentário Previdenciário (FAP). O FAP prevê alíquotas diferenciadas do Seguro de Acidente de Trabalho (SAT) para as empresas que investem e as que não investem em segurança e saúde dos trabalhadores. Com essa pressão - ainda que por interesses próprios das empresas que vão investir no combate às doenças ocupacionais - gera benefícios ao trabalhador. (BELEDELI, 2010).

Segundo a normativa, dos vários benefícios que podem ser criados, dois deles com relação ao tratamento da dor crônica se destacam o primeiro refere-se à criação de equipe multiprofissional, composta por médicos, enfermeiros, terapeutas corporais, profissionais de terapias complementares, fisioterapeutas, terapeutas ocupacionais, psicólogos e assistentes sociais. (BRASIL, Diário Oficial da União, 2003).

O segundo refere-se à criação de grupos de pessoas adoecidas por LER/DORT, que permite a socialização da vivência do adoecimento e da incapacidade, além do apoio psicológico para que se sintam amparados no que se refere às atividades no trabalho, com uma abordagem dos aspectos psicossociais e do sofrimento mental dos pacientes. (BRASIL, Diário Oficial da União, 2003).

A normativa prevê também toda a situação desconfortável a que os trabalhadores estão sujeitos, desde o diagnóstico até a discriminação da família e da sociedade em geral, ou seja, desde as represálias explícitas ou implícitas da direção da empresa quando da possibilidade de o paciente manifestar-se em relação às queixas de saúde, da 'desconfiança' do médico, que se julga 'enganado' pelo paciente, devido a longos períodos de tratamentos sem melhora significativa. (BRASIL, Diário Oficial da União, 2003).

\section{Métodos}

O presente estudo foi realizado através da metodologia qualitativa que possibilitou a aproximação para conhecer as experiências dos sujeitos, com técnicas de entrevistas, análise documental (relatórios e fichas médicas, relatórios anuais do Serviço Social da Indústria (SESI) e Laudos Ergonômicos), juntamente com anotações de acontecimentos no período de dois anos (2009 e 2010).

A pesquisa foi delimitada aos funcionários de nível operacional das linhas de produção que possui um total de 60 funcionários, 50\% são retornados do INSS por motivo de doença ocupacional, sendo a amostra composta por $33 \%$ desse universo.

Diante disso, os integrantes da pesquisa foram identificados a partir do relatório de retornados do INSS, especificamente por terem LER/DORT/Lombalgias, logo suas limitações enquanto portadores de dores crônicas ficaram comprovadas através de seus relatos e de consulta nas fichas médicas, onde consta o tratamento da doença desde o início.

Para tanto as entrevistas se deram em grupos, dentro das dependências da empresa, através de visita ao setor da produção, valendo-se de narrativa oral como troca de experiências no horário do almoço, abordando a realidade atual do Programa de QV da empresa nos seguintes pontos: se os trabalhadores vêem o sistema como adequado e quais melhorias na opinião deles são necessárias.

A análise dos dados se deu através da comparação dos relatos com as anotações sobre ocasiões específicas da postura da empresa sobre seu atual programa de QVT, dos documentos coletados, e das propostas de melhorias indicadas pelos sujeitos.

\section{Estudo de Caso}

A empresa pesquisada iniciou suas atividades em 1962, e, hoje direciona suas atividades, principalmente, para o segmento industrial e de serviços destacando-se na liderança no 
fornecimento de equipamentos de transmissão digital e instalação de redes de transmissão por fibras ópticas, com significativa participação no mercado de telecomunicações brasileiro.

Tornou-se, assim, um grupo de empresas e está presente em vários estados brasileiros, além de possuir mais de 1600 colaboradores. A matriz localizada na região de Sorocaba, São Paulo, onde foi realizada a pesquisa e é a holding do grupo, que abrange uma área de produção com 60 funcionários responsáveis pela montagem de equipamentos, onde são montados os equipamentos, e 140 colaboradores para a área administrativa.

Com relação ao trabalho, o conforto que a empresa disponibiliza para a execução das atividades é baixo, as bancadas, cadeiras e bancos, bem como alguns dos equipamentos utilizados não estão de acordo com as exigências dos laudos ergonômicos.

Os trabalhadores estão passando por uma época de sobrecarga de trabalho por conta de novos contratos, ou seja, longos períodos de horas extras, sem previsão de contratações, devido à morte do fundador da empresa e admissão da nova diretoria composta por seus filhos.

Com relação à cultura de QVT, ficou constatado que a empresa pesquisada faz somente o necessário, ou seja, o que está previsto na lei (a legislação que regulamenta as relações de trabalho no Brasil, enfatiza quase que exclusivamente os aspectos biológicos), não valoriza o trabalhador como seu diferencial competitivo, o que atualmente se vê não como modismo, mas como algo que veio para mudar toda uma geração de comportamento na área da Administração, mais especificamente em Gestão de Pessoas.

Especificamente na área de gestão de pessoas a empresa possui um Departamento Pessoal, onde são administrados os benefícios, contratações e a folha de pagamentos. Não possui a área de Recursos Humanos consolidada, que atue estrategicamente nas decisões da empresa e que trabalhe as ferramentas necessárias para a gestão de pessoas e não possui o setor de comunicação empresarial.

\subsection{Programa de Qualidade de Vida no Trabalho da empresa ' $Y$ '}

A empresa conta com uma enfermaria, com médico e enfermeira do trabalho e possui as seguintes atividades em seu programa de QVT, as atividades da Comissão Interna de Prevenção de Acidentes (CIPA) e o Programa de Ginástica Laboral que existe a cinco anos, desenvolvido pelo SESI.

Após o relatório ergonômico de 2009, os professores do SESI, elaboraram para 2010 uma nova carga horária para a Ginástica Laboral, que foi aceita pela diretoria. Consiste em aulas diárias aplicadas em 15 minutos no período da manhã.

No programa de Ginástica Laboral, existe um calendário anual com as atividades extras durante o ano. Através do Programa, o SESI faz a Avaliação Física dos empregados uma vez ao ano para verificar o índice de massa corpórea, que em 2010 teve um aumento de 8\% em relação a 2009 nos profissionais da produção. Dos trabalhadores estudados $30 \%$ estão acima do peso e hipertensos.

Nas aulas é enfatizada a importância da QV como um todo e especificamente em relação com o trabalho. Uma vez ao mês as aulas são diferenciadas, com relaxamento, conscientização sobre Tensão Pré Menstrual (TPM) - devido ao maior número de mulheres na produção - estresse e LER.

Há pouca participação dos funcionários nessas aulas, com relatos de que o chefe não chega a proibir, mas deixa a entender que não é para participar. E quando participam sentem o clima de negação.

$\mathrm{Na}$ época da Semana Interna de Prevenção de Acidentes do Trabalho (SIPAT), são desenvolvidas pela empresa, através de profissionais contratados e em parceira com o SESI, palestras sobre estresse e bom humor, ergonomia, determinados tipos de câncer como próstata, mama e de pele, programas de prevenção e atenção aos riscos de doenças do coração, exames de glicemia e pressão arterial. 
Anualmente a empresa desenvolve campanhas para as doenças sazonais, mais especificamente contra a gripe e palestras sobre tabagismo. Mensalmente são colocados nos murais, pelos professores do SESI, folders sobre assuntos de QVT.

Com relação aos investimentos em QVT, na reunião anual realizada em dezembro de 2009, o diretor da empresa enfatizou o investimento, mas no decorrer do ano, apenas algumas palestras foram realizadas sobre, câncer de próstata e pele, e as mudanças sugeridas no relatório ergonômico até o presente momento não tinha sido aprovadas.

A empresa oferece refeitório onde diariamente é servido o prato light (além de outras opções), que é pouco consumido, muito provavelmente devido à falta conscientização sobre a QV na alimentação.

\section{Resultados}

O setor estudado é a produção, localiza-se em andar térreo, a luminosidade é realizada artificialmente pelo auxílio de lâmpadas e naturalmente com auxilio de janelas e o período de trabalho das $07 \mathrm{~h}$ às $17 \mathrm{~h}$.

Possui trabalhadores do gênero masculino e feminino, em sua maioria feminino, com idade entre 30 e 54 anos, com tempo de trabalho entre 5 a 29 anos, e não possuem outro ofício. Referente ao percentual de Índice de Massa Corpórea (IMC), cerca de $70 \%$ está com peso normal e os outros $30 \%$ acima do peso.

Com relação à dor, segundo o último relatório ergonômico realizado em dezembro de 2009, $88 \%$ da amostra se queixam de dor nas regiões do pescoço, ombro, antebraço, punho, coluna lombar e cotovelos. A dor está presente nos últimos 12 meses e nos últimos sete dias, e a maioria dos trabalhadores já foi afastada do trabalho por motivos de lesões ocupacionais.

Historicamente no laudo ergonômico do ano de 2002, algumas alterações nos móveis foram realizadas no setor para evitar LER/DORT, mas como constatou nesse último relatório, há um risco moderado de lombalgia, que precisa ser corrigido.

Há na empresa o comportamento social de discriminação aos acometidos de dor. É comum ouvir dizer pelos colegas de serviço que os acometidos da dor, gostam de matar serviço.

Isso faz com que eles sofram sozinhos, sem ter com quem conversar. É da vontade deles mesmos, ou seja, $90 \%$ das opiniões fazerem parte de um grupo de pessoas que tenham o mesmo problema, acompanhado por um profissional da área da psicologia, possivelmente nas dependências da empresa, o que acaba por reforçar o sucesso de um grupo nas mesmas condições, estudado pelos autores Hoefel et al. (2004).

Pela pesquisa foi indicado como idéia e opinião, que se fosse permitido fazer a troca da ginástica laboral pela fisioterapia (visto que eles sentem dificuldade para participar da ginástica devido à dor, e os exercícios não são específicos para eles), seguida da reunião do então grupo de portadores de dor crônica.

Quando questionados o porquê de fazer essas atividades na empresa e não fora dela, a resposta foi unânime em dizer que se sentem constrangidos de matar serviço (é como se sentem aos olhos dos colegas de trabalho) e sem precisar se deslocar ganhariam mais tempo de trabalho.

Em sua totalidade, eles apresentam uma história laboral de resignação e trabalho com dor, mas preferem trabalhar a voltar para o INSS, como dizem. Sentem medo da depressão, que muitos deles já passaram enquanto estavam afastados, e acima de tudo, desejam sentirem-se úteis.

Com a morte do fundador e as mudanças decorrentes da nova diretoria, que não se pronunciou sobre o futuro da empresa, eles sentem o medo do desemprego, o que os faz muitas vezes calar ao invés de reivindicar melhores condições de trabalho. Por se encontrarem a muitos anos na mesma empresa, temem não conseguirem mais recolocação no mercado.

Cerca de $30 \%$ deles, gostariam de ter jornada de trabalho reduzida e melhor aceitação para os dias em que o pico da dor é mais intenso, ou seja, gostariam de receber consulta do médico da fábrica e ter o dia de descanso para aliviar a dor e o desânimo, que sentem por faltar alguém que os escute e os compreenda. O serviço de assistência médica para eles é ineficiente, houve reclamação 
em $80 \%$ da amostra.

A empresa é muito bem cuidada em sua aparência física, o que de certa forma chateia alguns trabalhadores, que acabam vendo altos investimentos mensais nos jardins, e eles sem a QVT adequada, ou seja, não se sentem valorizados, o pouco que a empresa faz nesse sentido é ineficiente e desperdício de dinheiro.

Tendo em vista os aspectos analisados, percebe-se que a sociedade como um todo ainda não está preparada para gerir pessoas que convivem com dor crônica. Infelizmente, nos relatos é comum ouvir frases que passam o preconceito ou a falta de compreensão, deixando aparente o descaso ou a sensação de que a dor seria desculpa, de pessoas da própria família dos acometidos e de seus amigos de trabalho.

Relatos como esses vêm de encontro ao que muitos estudiosos e até mesmo a própria Previdência Social indicou, para que sejam formados grupos com portadores de LER/DORT/Lombalgias como recurso de tratamento, com estratégias de enfrentamento como modos de diminuir a dor, a desesperança e a depressão que são decorrentes à doença.

Não obstante, o estudo comprovou que os tempos mudaram, mas a gestão de pessoas ainda está caminhando a lentos passos nessa área, desde as pesquisas de Limongi-França (1996) e Dejours (2003). Isso significa que o descaso e o sofrimento dos trabalhadores fazem parte da cultura da empresa estudada e talvez de outras tantas.

Ficou constatado também que é de extrema necessidade ouvir os trabalhadores ao se aplicar programas de QV, para que eles validem o que é necessário evitando o desperdício de dinheiro, como eles próprios dizem.

Os trabalhadores aqui estudados estão atentos ao ambiente de trabalho que está em constantes mudanças, o que acaba por gerar angústia e insegurança, como desemprego, exigências técnicas e psicológicas, excesso de trabalho e falta de valorização. Nesse contexto, pode-se constatar pelos relatos contados por eles, que existe uma desistência de reivindicar ou opinar sobre os métodos ineficazes do projeto de administração da QVT atual da empresa, que nesse caso apenas disfarça a realidade, em razão das situações citadas anteriormente.

\section{Considerações Finais}

A resposta para a pergunta inicial dessa pesquisa, sobre o que os trabalhadores que convivem com dor esperam da empresa, é a comprovação da ineficiência do Programa de QVT existente na empresa estudada e as opiniões dos funcionários que vivem essa realidade.

$\mathrm{Na}$ maioria das empresas, os trabalhadores, segundo seu dia-a-dia, conseguem visualizar melhorias realmente eficazes para suas limitações, que podem gerar eficácia no programa de QVT, mas na empresa estudada, infelizmente eles não têm abertura para propor essas melhorias. Ficou constatado que eles esperam das empresas o auxílio para cuidar de sua saúde e programas inclusão, prevenção, bem como investimentos.

O estudo reforçou a ideia de que é somente nesse contexto de visão holística e consulta do trabalhador, que se consegue encontrar respostas para criar ou melhorar os programas de QV existentes. E que a saúde do trabalhador ainda é segundo plano na empresa estudada, além de promover uma boa discussão sobre o tema QVT.

Para que o programa atual de QVT seja realmente eficiente, primeiramente são necessárias as trocas ou adaptações das bancadas, cadeiras e alguns instrumentos de trabalhos. Fica a sugestão da criação de um grupo de psico-fisioterapia (atividades de fisioterapia, com terapia de grupo para os que convivem com dor), e melhor tratamento por parte do médico da empresa para os trabalhadores que estão em dias onde o pico da dor é mais intenso.

Parte da observação mostra que a empresa, do ponto de vista de seu relacionamento com seus colaboradores internos, não é considerada socialmente responsável, passando uma imagem negativa, os quais não se sentem confortáveis com relação à QVT. 
Conclui-se que a empresa precisa reformular seu atual programa de QVT, pois o atual programa contém atividades relevantes para o trabalhador, no que diz respeito à prevenção de doenças do trabalho, mas ineficiente ao público que convive com dor crônica.

\section{Referências}

BELEDELI, M. Acidentes de trabalho no Brasil crescem 13,4\%. Net, Jornal do Comércio, Rio Grande do Sul, 22 fev. 2010. Disponível em: 〈http://jcrs.uol.com.br/site/noticia.php?codn=20561〉. Acesso em: 23 jun. 2010.

BRASIL. Diário Oficial [da] União, 10 de dezembro de 2003. Revisão da Norma Técnica sobre Distúrbios Osteomusculares Relacionados ao Trabalho-DORT. Disponível em: <http://www.ergonet.com.br/download/ler-dort-instrucao.htm>. Acesso em: 23 jun. 2010.

CHIAVENATO, I. Gestão de Pessoas: o novo papel dos recursos humanos nas organizações. 3 ed. Rio de Janeiro: Elsevier, 2008.

DATAPREV. (Empresa de Tecnologia e Informação da Previdência Social ). 2003. Disponívem em: $\quad<$ http://www81.dataprev.gov.br/sislex/imagens/paginas/38/inss-dc/2003/anexos/IN-DC-98ANEXO.htm>. Acesso em 23 jun. 2010.

DEJOURS, C.; ABDOUCHELI, E.; JAYET, C. Psicodinâmica do trabalho: contribuições da escola Dejouriana à análise da relação prazer, sofrimento e trabalho. São Paulo: Atlas, 2009.

DEJOURS, C. A banalização da injustiça social. 7. ed. Rio de Janeiro: FGV, 2006.

O fator humano. 5. ed. Rio de Janeiro: FGV, 2005.

Cortez, 2003.

A loucura do trabalho estudo de psicopatologia do trabalho. 5. ed. São Paulo:

FUNDACENTRO (Fundação Jorge Duprat Figueiredo de Segurança e Medicina do Trabalho Ministério do Trabalho e Emprego)., abr., 2008. 28 de Abril - Dia Mundial da Segurança e da Saúde no $\quad$ Trabalho $\quad$ Disponível em : $<$ http://www.fundacentro.gov.br/conteudo.asp?D=CTN\&C=904\&menuAberto=64>. Acesso em: 23 jun. 2010.

GRAZIANO, G. O.; FARAH, O. E., GRAZIANO, I. O. Gestão Social: qualidade de vida no trabalho. $2005 . \quad$ Disponível em: <http://www.ead.fea.usp.br/semead/8semead/resultado/trabalhosPDF/306.pdf>. Acesso em: 01 mai. 2010.

HOEFEL, M. G.; JACQUES, M. G.; AMAZARRAY, M. R.; MENDES, J. M. R.; NETZ, J. A. Uma proposta em saúde do trabalhador com portadores de LER/DORT: grupos de ação solidária. $2004 . \quad$ Disponível

<http://www.revistasusp.sibi.usp.br/scielo.php?script=sci_arttext\&pid=S151637172004000100004\&lng=en\&nrm=iso>. Acesso em: 23 jun. 2010.

JACQUES, M. G.; CODO, W. Saúde mental \& trabalho: leituras. Rio de Janeiro: Vozes, 2002. 
KANIKADAN, A. Y. S.; ELENIR, H. V.; BOSE, M.; SHINYASHIKI, R. T. Gestão da Qualidade de Vida no Trabalho e Estratégia Empresarial: Estudo de Caso na empresa X. Mestrado. FEA/USP, São Paulo, 2005.

LACAZ, F. A. C. Qualidade de vida no trabalho e saúde/doença. 2000. Disponível em: <http://www.scielo.br/scielo.php?pid=S1413-81232000000100013\&script=sci_arttext\&tlng=pt $>$.

Acesso em: 23 jun. 2010.

LIMONGI-FRANÇA, A. C. Qualidade de vida no trabalho - QVT: conceitos e práticas nas empresas da sociedade pós-industrial. 2. ed. São Paulo: Atlas, 2008.

LIMONGI-FRANÇA, A. C. Indicadores empresariais de qualidade de vida no trabalho: esforço empresarial e satisfação dos empregados no ambiente de manufaturas com certificação ISO 9000. 1996. 296 f. Tese (Doutorado em Administração) - Faculdade de Economia, Administração e Contabilidade, Universidade de São Paulo, São Paulo. 1996.

NUNES, E. E.; MENDES, J. M. R. A trajetória do trabalhador portador de LER/DORT: Afinal que caminho é esse? Revista Virtual Textos \& Contextos. n. 1, ano I, nov. 2002. Disponível em: <http://revistaseletronicas.pucrs.br/revistapsico/ojs/index.php/fass/article/view/932>. Acesso em: 01 mai. 2010.

OLIVEIRA, R. Qualidade de Vida no Trabalho - QVT e Responsabilidade Social Empresarial - RSE: Um Estudo sobre a satisfação de QVT com funcionários voluntários em programas RSE. 2008. 137 f. Tese (Mestrado em Administração) - Universidade Metodista de São Paulo, Faculdade de Ciências Administrativas, São Bernardo do Campo. 2008.

RECHZIEGEL, W.; VANALLE, R. M.; LIMONGI-FRANÇA, A. C. Satisfação com a qualidade de vida no trabalho no nível operacional: um estudo de caso em uma grande empresa do setor de autopeças. $2000 . \quad$ Disponível em: <http://www.abepro.org.br/biblioteca/ENEGEP2001_TR44_0616.pdf $>$. Acesso em: 23 jun. 2010.

RODRIGUES, P.; ALVES, G.; SILVA, N. R. Trabalho e subjetividade: um estudo de caso sobre a saúde de trabalhadores na linha de produção da indústria farmacêutica. 2008. Disponível em:

<http://www.estudosdotrabalho.org/anais6seminariodotrabalho/patriciarodriguesgiovannialvesnilso nrsilva.pdf $>$. Acesso em: 23 jun. 2010.

RUMAQUELLA, M. R. Postura de trabalho relacionada com as dores na coluna vertebral em trabalhadores de uma indústria de alimentos: estudo de caso. 2009. $137 \mathrm{f}$. Tese. (Mestrado em Design) - Faculdade de Arquitetura, Artes e Comunicação, Universidade Estadual Paulista, Bauru. 2009.

VASCONCELOS, A. F. Qualidade de Vida no Trabalho: origem, evolução e perspectivas. 2001. Caderno de Pesquisas em Administração, São Paulo, v. 08, n. 1, jan./mar. 2001. Disponível em: <http://www.ergonomia.ufpr.br/PB\%20qvt_origem.pdf>. Acesso em: 01 mai. 2010.

VELOSO, H. M.; BOSQUETTI, M. A.; LIMONGI-FRANÇA, A. C. A concepção gerencial dos programas de qualidade de vida no trabalho (QVT) no setor elétrico brasileiro. 2006. Disponível em: <http://www.ead.fea.usp.br/semead/8semead/resultado/trabalhosPDF/308.pdf $>$. Acesso em: 23 jun. 2010. 